\title{
A GIS-based habitat suitability model for the mountain nyala tragelaphus buxtoni in the southeastern highlands of Ethiopia and its implication for conservation
}

\begin{abstract}
Mountain nyala Tragelaphus buxtoni is one of the endangered and endemic flagship species in Ethiopia. The goal of this study was to identify and map the distribution of suitable habitats for the mountain nyala in the southeastern highlands of Ethiopia where the species can be found. The following two questions were addressed in this study 1 what are the major abiotic, biotic, and anthropogenic factors that determine the suitable habitats for the mountain nyala in the southeastern highlands of Ethiopia? And,2 where are the areas of best habitat suitability for the mountain nyala? Environmental and anthropogenic variables, such as landform and/or topography (i.e., slope), elevation, vegetation cover (i.e., trees, shrubs, and herbs cover), towns, and roads were included to develop a GIS (Geographic Information System) habitat suitability model for the mountain nyala. The model predicted that a total of $2,436.98 \mathrm{~km} 2$ of suitable habitats are currently available for the endangered mountain nyala in Ethiopia. Three environmental variables, landform and/or topography (e.g., slope), vegetation cover (i.e., trees, shrubs, and herbs cover), and elevation, were the most important predictors having the greatest contribution to the habitat suitability model. The model suggested that habitat fragmentation is a common problem for the survival of the mountain nyala throughout its ranges of distribution. Thus, future conservation and management action should gear towards solving this problem through designing appropriate corridors that help connect the fragmented suitable habitat patches for this endangered flagship species in Ethiopia.
\end{abstract}

Volume 3 Issue 3 - 2018

\author{
Solomon Ayele Tadesse,' Burt P Kotler ${ }^{2}$ \\ 'Department of Natural Resources Management, College of \\ Agriculture and Natural Resource Sciences, Debre Berhan \\ University, Ethiopia \\ 2Mitriani Department for Desert Ecology, Ben-Gurion \\ University of the Negev, Israel
}

\begin{abstract}
Correspondence: Solomon Ayele Tadesse, Department of Natural Resources Management, College of Agriculture and Natural Resource Sciences, Debre Berhan University, PO Box 445, Debre Berhan, Ethiopia, Tel +25I I II68 I544 0 (office), +25I94670 3660 (mobile), Fax +25। I II68 I2065 Email solomon.ayele1972@gmail.com
\end{abstract}

Received: December 16, 2017 | Published: May 29, 2018

Keywords: environmental and anthropogenic variables, flagship species, habitat fragmentation, ranges of distribution

\section{Introduction}

Mountain nyala Tragelaphus buxtoni is one of the endangered and endemic flagship species in Ethiopia. ${ }^{1,2}$ The species is confined in its distribution to the southeastern highlands of Ethiopia, bounded by the Chercher Mountains in the north and the Bale Mountains in the south. ${ }^{3,4}$ Currently, mountain nyala is known to occur in six different locations in Ethiopia. From north to south, these sites are: Kuni Muktar, Dindin and Arba Gugu Forests, Munessa-Shashemene Forests, Mount Kaka, Galama-Chilalo Forest Priority Area (FPA), and the Bale Mountains (Figure 1). ${ }^{5}$ The most prominent population of mountain nyala is found in the Bale Mountains. ${ }^{3,6-10}$ Mountain nyala are commonly reported to be found in a mosaic of high-altitude woodland, bush-land, heath-land, moorland, and valley-bottom grassland, ranging from $1600 \mathrm{~m}$ up to $4300 \mathrm{~m}$ above sea level, ${ }^{3}$ but they are mostly concentrated between $1800 \mathrm{~m}$ and $4000 \mathrm{~m}$ in the heath-land and alpine mesic habitats. ${ }^{8,11,12}$ They prefer steep terrains and dense vegetation for concealment, thermal cover, year-round forage, and predator avoidance (Table 1). ${ }^{3,8,13}$

Mountain nyala require a relatively large home range and diverse habitat resources, ${ }^{1,3,8,10}$ therefore, they need management of landscapes rather than isolated patches of habitat. Moreover, since 2000, there have been several sizable populations identified that have yet to be acknowledged by the scientific or wildlife conservation communities in Ethiopia. ${ }^{3,13}$ So, scientific knowledge in regard to the distribution and availability of suitable habitats for the mountain nyala in Ethiopia are crucial to enhance the conservation and management of the species and its habitats.

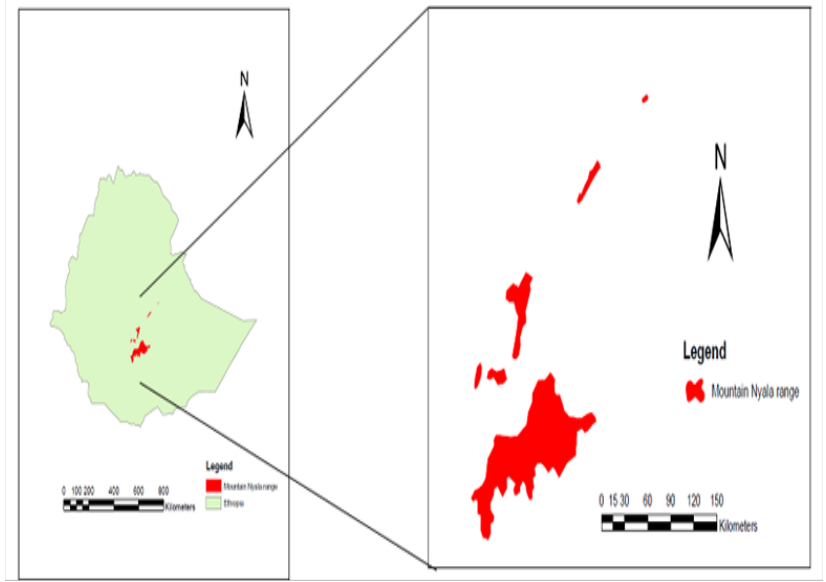

Figure I Distribution map of the mountain nyala in the southeastern highlands of Ethiopian. ${ }^{5}$ 
Table I Environmental and anthropogenic factors affecting the suitable habitats for the mountain nyala

\begin{tabular}{ll}
\hline Factors & References \\
\hline Landform and/or topography (e.g. slope) & $3,5,9,10,13,25$ \\
Elevation & $3,7,8,9,10,13,25$ \\
$\begin{array}{l}\text { Vegetation cover (i.e. trees, shrubs, and herbs } \\
\text { cover) }\end{array}$ & $3,7,8,9,10,13,25$ \\
Towns and roads & $6,9,25$ \\
\hline
\end{tabular}

Habitat suitability models are the simplest and perhaps the most frequently used form of ecological models. ${ }^{15}$ They are intended to be general indicators of habitat suitability that are easily and reputably applied under field conditions. ${ }^{16}$ However, their uses are highly dependent on the ecological interactions and the spatial and temporal scales that are pertinent to land management concerns and the species of interest. ${ }^{17,18}$ Habitat suitability modeling serves as a tool for predicting the suitability or quality of habitats for a particular species based on known affinities of environmental parameters. ${ }^{19,20}$

The habitat suitability models assume that habitat is an important factor in determining the presence and relative abundance of the species in question..$^{20,21}$ The selection of appropriate environmental variables not only depends on the species studied, but also on the costs of collecting the variables and the purpose of the empirical data. ${ }^{22}$ Minimizing the number of variables in the habitat suitability model serves two purposes: the model becomes more easily applied, and the likelihood of model over-fitting is reduced..$^{23}$ However, to maximize the usefulness of the habitat suitability models, it is important that they should be constructed using as much reliable priori information as possible. ${ }^{24}$

Precipitation and temperature are known to have direct influence on vegetation structure, distribution, and diversity., ${ }^{8,225}$ Moreover, previous studies suggest that vegetation type, structure, distribution, and diversity are known to heavily affect the suitable habitats for the mountain nyala..$^{9,10,13,25}$ In addition, precipitation and temperature are directly influenced by elevation (i.e. altitude) of the landscape; therefore, elevation better predicts the suitable habitats for the mountain nyala. ${ }^{9,10,13,25} \mathrm{So}$, in order to avoid the redundant usage of environmental variables, both precipitation and temperature were excluded from the GIS-based habitat suitability model for the mountain nyala. Furthermore, previous studies noted that individual rural homesteads, livestock herds, and other human activities, such as deforestation and illegal hunting are dispersed throughout the whole ranges of the mountain nyala in Ethiopia; $;^{3,10,13,25}$ therefore, it was not possible to include individual rural settlements, livestock grazing, deforestation, and illegal hunting pressures into the present model. However, other anthropogenic factors, such as roads and towns determining the presence or absence of the mountain nyala in a specific habitat were included in the model.

Based on previous literature reviews, ${ }^{3,6,8,9,10,13,25}$ the following environmental and anthropogenic variables were only included: landform and/or topography (i.e. slope), elevation, vegetation cover (i.e. trees, shrubs, and herbs cover), towns, and roads. The goal of this study was to identify and map the distribution of the suitable habitats for the mountain nyala in the southeastern highlands of Ethiopia where the species can be found. Some previous studies noted that wildlife species are more abundant in some habitats than others, with various environmental (i.e., biotic and abiotic) and anthropogenic factors determining the presence or absence of a species in a specific habitat. ${ }^{13,14}$ This suggests that there are intimate and complex relationships between a species and its habitats. Therefore, the following two questions were addressed in this study: (1) what are the major abiotic, biotic, and anthropogenic factors determining the suitable habitats for the mountain nyala in the southeastern highlands of Ethiopia? And (2) where are the areas of best habitat suitability for the mountain nyala.

\section{Material and methods}

\section{Extracting environmental and anthropogenic variables data}

Firstly, it was checked if all the raster data have defined coordinate systems. It was chosen that the GCS_WGS_1984 as the appropriate data frame coordinate system in which all the data have been projected. The base map of Ethiopia was accessed from the GIS online link using: http://www.arcgis.com/home/group.html (Owner: kevkoy; date modified: 7/7/2010). Elevation, vegetation cover (i.e. trees, shrubs, and herbs cover), roads, and towns' raster data for Ethiopia were obtained from the following web link: (http://ethgis.colostate. edu/WebContent/WS/GISTraining/7_0_GISDataSources.html). Moreover, the slope raster data for Ethiopia were derived from the elevation raster data of the country using slope $3 \mathrm{D}$ analyst tool where the elevation data were used as input raster and the slope as output raster of Ethiopia. The present distribution map of the mountain nyala was geo-referenced and digitized Evangelista et al. ${ }^{3}$ by overlapping it on the digital map of Ethiopia. Then, it gave the range of the current distribution map of the six localized populations of the mountain nyala in the southeastern highlands of Ethiopia as shown in Figure 1.

\section{Arc GIS processing for habitat suitability analysis}

Adding a process to clip the environmental layers based on the current distribution map of mountain nyala. Since the environmental variables data (i.e. elevation, vegetation cover (i.e. trees, shrubs, and herbs cover), slope, roads, and towns raster data) were for the whole Ethiopia, we had to clip the data to concentrate the analyses only to the areas presently occupied by the mountain nyala. To do so, each Ethiopian environmental variable data was clipped using the clipping tool found in the data management where each environmental variable data was used as an input raster and the present distribution map of the mountain nyala as the feature clip dataset to create a new output raster shape file for each environmental variable. Accordingly, each environmental data layer was clipped as described before. It was reclassified that the clipped trees, shrubs, and herbs cover raster data into five classes using equal intervals method in the reclassify spatial analyst tool. Furthermore, the values of the reclassified clipped raster data of trees, shrubs, and herbs cover were calculated and summed using the raster calculator in the spatial analyst tool. So, the two calculated and summed raster data represent the clipped vegetation raster data of the study area.

Adding a process to select the preferred elevation, slope, and vegetation into the suitable habitats for the mountain nyala. Previous studies suggested that the preferred elevation for the mountain nyala ranges from $1800 \mathrm{~m}$ to $4000 \mathrm{~m} .^{8,11,12}$ Moreover, mountain nyala prefer steep slope terrains so as to easily escape from risks of predation. On top of this, mountain nyala prefer dense vegetation for concealment, thermal cover, year-round forage, and predator avoidance., ${ }^{3,8,13}$ Accordingly, the preferred elevation raster data $(1800 \mathrm{~m}-4000 \mathrm{~m})$ were 
selected for the mountain nyala using extract by attributes (spatial analyst) tool. Similar procedures were followed to select the preferred slope ([value] $\geq 3$ ) and vegetation ([value] $\geq 3$ ) raster data. The values range from 1 to 5 where 1 represents lowest slope or vegetation cover raster data, but 5 represents highest slope or vegetation cover raster data.

Adding a process to buffer clipped town polygons and clipped road polylines. The buffer analysis tool was used to buffer the clipped town polygons. Clipped town polygons were used as input feature and town buffer polygons were used as output feature. Some previous studies suggested that a buffering distance of $5000 \mathrm{~m}$ was used in the town buffer analysis to develop a GIS-based habitat suitability models for large body-sized wild animal species. ${ }^{22,25}$ This implies that habitats that are situated $5000 \mathrm{~m}$ away from towns are considered to be suitable for the mountain nyala in the southeastern highlands of Ethiopia. A similar procedure was used to buffer the clipped road polylines with a buffering distance of $300 \mathrm{~m} \cdot{ }^{25}$ This suggests that habitats that are situated $300 \mathrm{~m}$ away from roads are supposed to be suitable habitats for the mountain nyala.

Adding a process to intersect mountain nyala habitat suitability criteria. This process helps define the suitable habitats for the mountain nyala because the intersect tool allows to integrate multiple input layers and create a new layer that contains only the features falling within the spatial extent which are common to all the input layers. ${ }^{22,25}$ First, all the raster data were converted to polygon layers using the raster to polygon conversion tool. Accordingly, the intersect analyst tool was used to identify and map the suitable habitats for the mountain nyala in the southeastern highlands of Ethiopia based on the input polygon layers containing selected elevation, vegetation, slope, areas buffered from towns, and roads.

Adding a process to dissolve the intersected polygons. As the objective of this study was to identify and map the predicted suitable habitats for the mountain nyala in the southeastern highlands of Ethiopia, this process helps merge all the intersected polygons together using the dissolve tool in the data management. The detailed steps used to construct the habitat suitability model for the mountain nyala were shown in the flowchart (Figure 2).

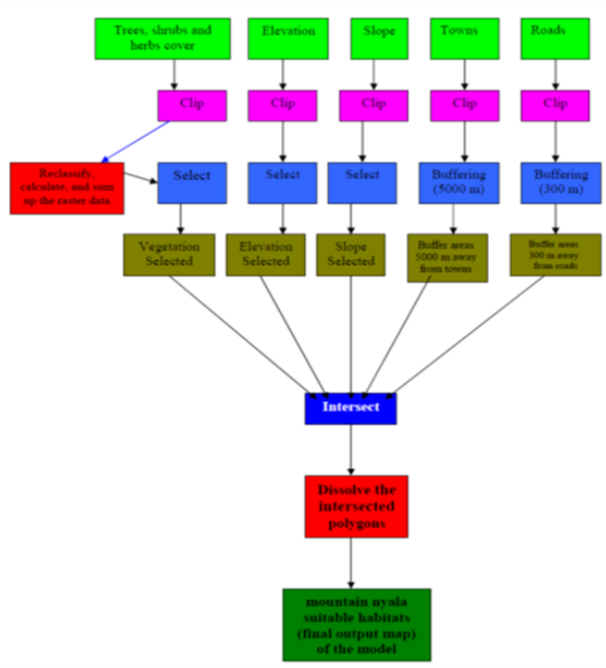

Figure 2 Flowchart of the processes used to build the habitat suitability model for the six localized populations of the mountain nyala in the southeastern highlands of Ethiopia.
Running the final habitat suitability model for the mountain nyala. Once the intersected polygons of the selected environmental and anthropogenic variables were dissolved together as illustrated in Figure 2, the model was run to get the final map of the suitable habitats for the mountain nyala and then combined with the current ranges of the species as shown in Figure 3.

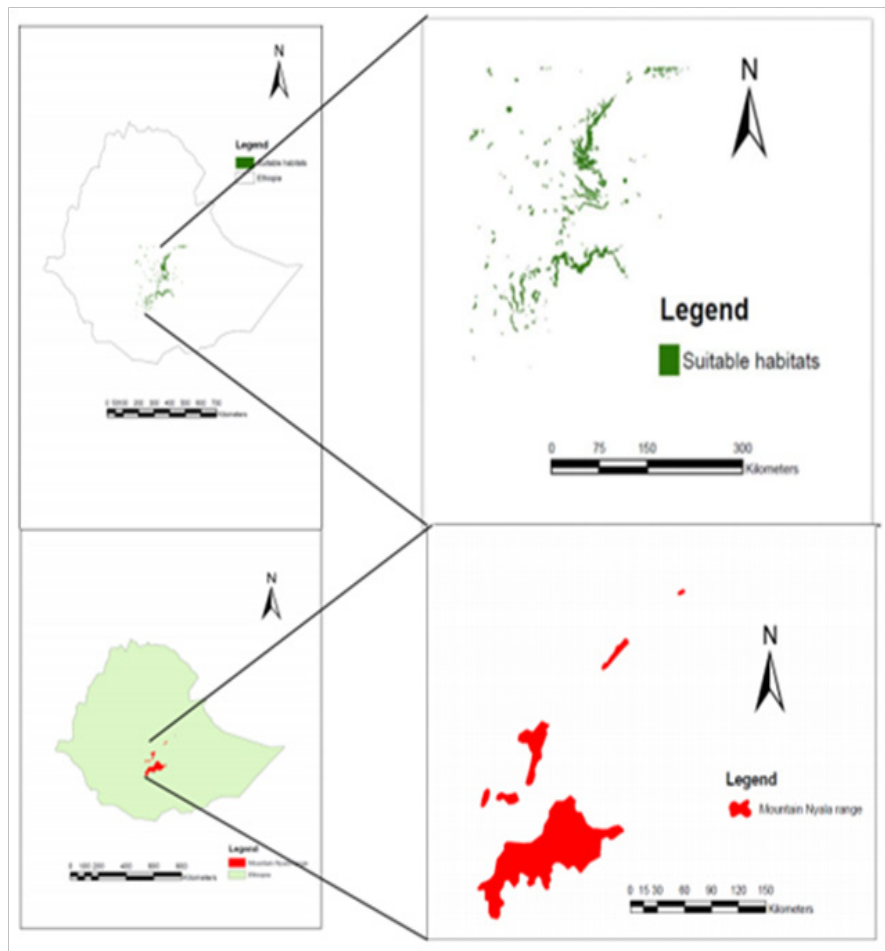

Figure $3 \mathrm{~A}$ final map showing the available suitable habitats for the mountain nyala in the southeastern highlands of Ethiopia. The current ranges of mountain nyala was included to show how the predicted suitable habitats are correlated to the current ranges of mountain nyala in Ethiopia.

\section{Results}

Three environmental variables, landform and/or topography (e.g. slope), vegetation cover (i.e. trees, shrubs, and herbs cover), and elevation, were the most important predictors having the greatest contribution to the habitat suitability model (Table 2 ). The habitat suitability model predicted that a total of $2,436.98 \mathrm{~km}^{2}$ suitable habitats are currently available for the six localized populations of the endangered and endemic mountain nyala in the southeastern highlands of Ethiopia (Figure 3). Moreover, the result suggested that most of the suitable habitats are concentrated in the eastern mountainous terrain where the most prominent populations of the mountain nyala are actually found, particularly in the Bale Mountains National Park where there is better protection of the mountain nyala population together with its natural suitable habitats. Furthermore, the interconnected suitable habitats are found in the steep sky islands which are inaccessible to human settlement, farm expansion, and free-range livestock grazing. However, those suitable habitats which are found in the gentle slopes of the central and western ranges of the mountain nyala are highly fragmented. This could happen due to the accessibility of the areas to high human and livestock activities including agricultural land expansion, overgrazing due to free-range livestock grazing, fire, deforestation, settlement, and urbanization. 
Table 2 The relative contribution of predictor variables to the habitat suitability model for the mountain nyala in the southeastern highlands of Ethiopia

\begin{tabular}{ll}
\hline Predictor variable & $\begin{array}{l}\text { Percent } \\
\text { contribution }\end{array}$ \\
\hline Landform and/or topography (e.g. slope) & 37.6 \\
Elevation & 24.8 \\
Vegetation cover (i.e. trees, shrubs, and herbs cover) & 29.2 \\
Towns and roads & 8.4 \\
\hline
\end{tabular}

\section{Discussion}

GIS-based spatial models are commonly used to predict species occurrence $^{22,25}$ and also identify critical habitats ${ }^{26}$ therefore, they have been popular among wildlife managers. ${ }^{27,28}$ The main outputs of the final GIS-based habitat suitability model: Hillman ${ }^{1}$ identified the major abiotic, biotic, and anthropogenic factors determining and predicting the suitable habitats for the mountain nyala; and $\mathrm{IUCN}^{2}$ identified, mapped, and quantified the available suitable habitats for the six localized populations of the mountain nyala in the southeastern highlands of Ethiopia. However, due to the complex negative impacts of human and livestock disturbances including deforestation, overgrazing, agricultural land expansion, fire, illegal settlement, urbanization, the current ranges of mountain nyala and the predicted suitable habitats are more fragmented as seen in Figure 3. Unless human and livestock induced impacts are controlled and minimized, it is an inevitable fact that the predicted suitable habitats will be changed into marginal habitats for the mountain nyala. Other studies also suggested that the mountain nyala is currently distributed in both suitable and marginal habitats that are negatively affected by intensive human interference and livestock competition..$^{3,5,6,9,10,13}$ However, the predicted suitable habitats with the help of the GIS model revealed that most of the current suitable habitats for the mountain nyala are found being concentrated (i.e. in the form of strips) in the eastern escarpment especially in gorgy terrains that are inaccessible to human settlement, agricultural land expansion, poaching, and free-range livestock grazing.

As it was shown in Table 2, three predictor variables were the most important in having the greatest contribution to the habitat suitability model. Landform and/or topography (e.g. slope) was the strongest predictor, which should not be surprising given that mountain nyala needs steep slope to escape from poaching and also for predator avoidance. This is why the predicted suitable habitats of the GIS model revealed that most of the current suitable habitats for the mountain nyala are found concentrated (i.e. in the form of strips) in the eastern escarpment especially in rugged terrains that are inaccessible to human settlement, agricultural land expansion, poaching, and freerange livestock grazing. Vegetation cover (i.e. trees, shrubs, and herbs cover) was the second strongest predictor. As the mountain nyala is illegally hunted by the local people for bush meat and skin purposes, $3,8,13$ it has good reasons to avoid people. Moreover, dense vegetation may serve the mountain nyala as a source of forage and concealment from strong sun especially during the heat of the day. The third variable to strongly affect the predicted suitable habitat is elevation because the mountain nyala is often found in high altitude areas so as to avoid human and livestock disturbances. Previous studies also noted that mountain nyala prefer steep terrains and dense vegetation for concealment, thermal cover, year-round forage, and predator avoidance. . $^{3,8,13}$

For large body-sized wild animal species, such as the mountain nyala, this GIS-based habitat suitability modeling approach performs best at large spatial scale (e.g. landscape scale). ${ }^{11,25}$ However, at small spatial scale, the GIS-based habitat suitability model may not be appropriate since presence and absence data are highly subjective due to the extensive ranges, elusive nature to detect in the dense vegetation, and the movement patterns of mobile species, such as the mountain nyala. ${ }^{25}$ In addition, the data required for empiricalbased models may not be available or may be difficult to acquire. ${ }^{23}$ In such cases, models that use qualitative information (i.e. expert knowledge) about target wild animal species may be a good approach for spatially quantifying relationships between wild animals and their environments/habitats..$^{28,30}$ For example, expert-based modeling has been practiced by wildlife managers for decades and continues to be a valuable tool even nowadays. ${ }^{31}$ Furthermore, by using the behavioral approach based on correlating activity densities of the study animals (e.g. the mountain nyala) with the influential habitat variables, one could develop a statistical habitat suitability model at a small spatial scale that can complement the GIS-based habitat suitability model. ${ }^{9,13,17,32}$

Factors, such as livestock grazing, deforestation, and illegal hunting pressures could not be included into the present model. This is because they are dispersed throughout the whole ranges of the mountain nyala in Ethiopia. ${ }^{3,10,13,25}$ However, by using the behavioral approach based on activity densities; those factors could be successfully included into the statistical habitat suitability model at small spatial scale. ${ }^{13,17,32}$ This is because the suitable habitats can be directly inferred from the behavioral responses (i.e. activity densities, time budgets, foraging behaviors, etc.) of the mountain nyala. Under such circumstances, combining the GIS-based approach with that of the behavioral-based approach may help build a comprehensive habitat suitability model that best predicts the suitable habitats both at large and small spatial scales especially for large body-sized animal species, such as the mountain nyala.

Based on the findings of this study, management interventions should prioritize and give more focus for the conservation of the current predicted suitable habitats together with the prevailing mountain nyala populations in Ethiopia. Moreover, future conservation and management action should focus on solving the problem of habitat fragmentation through designing appropriate corridors that help connect most of the fragmented suitable habitat patches over the whole ranges of the mountain nyala in Ethiopia. Corridors can also help mountain nyala to expand in their ranges of distribution or even be reintroduced. By doing so, the mountain nyala which are found in the marginal habitats might be attracted to the predicted suitable habitats as far as they can meet their habitat requirements. ${ }^{3,5,6,13}$

\section{Conclusion}

Habitat suitability model may serve as a basis for promoting the conservation and management of the six localized populations of the endangered mountain nyala and its natural suitable habitats in Ethiopia. For example, as shown in the final map of the suitable habitats, the present GIS-based habitat suitability model suggested that habitat fragmentation is a common problem for the survival of the mountain nyala throughout its ranges of distribution in Ethiopia. 
Thus, to safeguard the endangered and endemic mountain nyala from foreseeable extinction, future conservation and management action should gear towards solving the problem of habitat fragmentation through designing appropriate corridors that help connect the fragmented suitable habitat patches over the whole ranges of the mountain nyala in Ethiopia. The distribution and abundance of mountain nyala is negatively affected by the impacts of humans and livestock disturbances. Therefore, human and livestock encroachments should be controlled or minimized from affecting the suitable habitats of the mountain nyala throughout its ranges of distribution in Ethiopia.

\section{Acknowledgements}

First of all, our heartfelt thanks go to Dr. Aviva Peeters for her extraordinary willingness, unlimited assistance, and guidance in any matters concerning the Arc GIS 10 program whenever and wherever we needed. We have really learnt a lot from the fruitful discussions that we had, and have benefited a lot from her experiences. The authors also forward their gratitude to Debre Berhan University for funding this research.

\section{Funding}

The authors would like to send their gratitude to Debre Berhan University for covering all sources of the research funding that helped in the design of the study and also in writing of the manuscript.

\section{Authors' contribution}

SAT designed the study and wrote the manuscript. BPK wrote and revised the manuscript. Both authors revised and approved the final manuscript.

\section{Competing interests}

The authors declare that there are no competing interests.

\section{References}

1. Hillman JC, Hillman SM. The mountain nyala (Tragelaphus buxtoni) and Simien fox (Canis simensis) in the Bale Mountains National Park. Walia. 1987;10:3-6.

2. IUCN. Red list of threatened species in 2008 .

3. Evangelista P, Swartzinski P, Waltermire R. A profile of the mountain nyala (Tragelaphus buxtoni). African Indaba. 2007;5(2):1-48.

4. Refera B, Bekele A. Population status and structure of mountain nyala in Bale Mountains National Park, Ethiopia. African Journal of Ecology. 2004;42(1):1-7.

5. Malcolm J, Evangelista P. The range and status of the Mountain Nyala. Ethiopia: A report to the Ethiopian Wildlife Conservation Department, Addis Ababa; 2005. 43 p.

6. Evangelista P, Norman J, Swartzinki P, et al. Assessing habitat quality of the mountain nyala (Tragelaphus buxtoni) in the Bale Mountains, Ethiopia. Current Zoolog. 2012;58(4):525-535.

7. Brown L. Ethiopia's elusive mountain nyala. Animals. 1969a;(12):340344.

8. Brown L. Observation of the status, habitat, and behavior of mountain nyala (Tragelaphus buxtoni) in Ethiopia. Mammalia. 1969b;33(4):545597.
9. Mamo Y. Ecology and conservation of mountain nyala (Tragelaphus buxtoni) in Bale Mountains National Park, Ethiopia. UK: PhD Dissertation, University of Aberdeen; 2007. 201 p.

10. Atickem A, Loe Le, Langangen Ø, et al. Estimating population size and habitat suitability for mountain nyala in areas with different protection status. Animal Conservation. 2010;14(4):409-418.

11. Kingdon J. The Kingdon field guide to African mammals. New Jersey: Princeton University Press; 1997.

12. Yalden DW, Largen MJ. The endemic mammals of Ethiopia. Mam Review. 1992;22(34):115-150.

13. Tadesse SA, Kotler BP. Habitat quality and foraging ecology of mountain nyala (Tragelaphus buxtoni) in the Munessa Forest and the Bale Mountains National Park, south-eastern Ethiopia. Germany: LAP LAMBERT Academic Publishing; 2014. 192 p.

14. Morris DW. Ecological scale and habitat use. Ecology. 1987;68(2):362369.

15. Schamberger ML, Oneil LJ. Concepts and constraints of habitat model testing. Verner J, Morrison ML, Ralph CJ, editors. Wildlife 2000, Modeling habitat relationships of terrestrial vertebrates. Madison: University of Wisconsin Press; 1986.

16. Uhmann TV, Kenkel NC, Baydack RK. Development of a habitat suitability index model for burrowing owls in the eastern Canadian prairies. Journal of Raptor Research. 2001;5(4):378-384.

17. Druce DJ. Species requirements, coexistence and habitat partitioning at the community level: rock hyrax and klipspringer. $\mathrm{PhD}$ dissertation. Durban: University of KwaZulu-Natal; 2005.

18. Standards for the development of suitability index models, Ecological service manual 103. Washington: US Department of the Interior, Fish and Wildlife Service; 1981.68 p.

19. Morrison ML, Margot BG, Mdknnan RW. Wildlife habitat relationships: concepts and applications. USA: Univ. Wisconsin Press; 1998.

20. Van Horne B, Wiens JA. Forest bird habitat suitability index models and the development of general habitat models. Fish and Wildlife Research. 1991.

21. Farmer AH, Armbruster MJ, Terrell JW, et al. Habitat models for land use planning: assumptions and strategies for development. Transactions of the North American Wildlife and Natural Resources Conference. 1982;(47):47-56.

22. Store R, Jokimäki J. A GIS-based multi-scale approach to habitat suitability modeling. Ecological Modelling. 2003;169(1):1-15.

23. Jeffers JNR. Modeling. New York: Chapman and Hall; 1982.

24. Johnson DH. The comparison of usage and availability of measurements for evaluating resource preference. Ecology. 1980;61:65-71.

25. Evangelista P, Norman J, Lakew B. Predicting habitat suitability for the endemic mountain nyala in Ethiopia. Wild Res. 2008;(35):409-416.

26. Turner JC, Douglas CL, Hallum CR, et al. Determination of critical habitat for the endangered Nelson's bighorn sheep in southern California. Wildlife Society Bulletin. 2004;32(2):427-448.

27. Osborne PE, Alonso JC, Bryant RG. Modelling landscape-scale habitat use using GIS and remote sensing: a case study with great bustards. Journal of Applied Ecology. 2001;38(2):458-471.

28. Yamada K, Elith J, Mccarthy M, et al. Eliciting and integrating expert knowledge for wildlife habitat modeling. Ecological Modelling. 2003;165(2):251-264. 
29. Clevenger A, Wierzchowski J, Chruszcz B, et al. GIS-generated, expertbased models for identifying wildlife habitat linkages and planning mitigation passages. Conservation Biology. 2002;16(2):503-514.

30. Stoms DM, Davis FW, Cogan CB. Sensitivity of wildlife habitat models to uncertainties in GIS data. Photogrammetric Engineering and Remote Sensing. 1992;58:843-850.
31. Drew A, Wiersma Y, Huettmann F. Predictive species and habitat modeling in Landscape Ecology: Concepts and Applications. New York: Springer Publishing; 2001. 314 p.

32. Tadesse SA, Kotler BP. Habitat choices of nubian ibex (Capra nubiana) evaluated with a habitat suitability modeling and isodar analysis. Israel Journal of Ecology and Evolution. 2010;56(1):55-74. 